\title{
Pseudomyxoma Peritonei: A Need to Establish Evidence-Based Standard of Care-Is This the Right Trial?
}

\author{
Terence C. Chua, BScMed (Hons) ${ }^{1}$, Khaled Al-Mohaimeed, MBBS, FRCS ${ }^{3}$, Winston Liauw, MBBS, FRACP ${ }^{2}$, \\ and David L. Morris, MD, PhD $^{1,3}$ \\ ${ }^{1}$ Department of Surgery, St George Hospital, Sydney, Australia; ${ }^{2}$ Department of Medical Oncology, St George Hospital, \\ Sydney, Australia; ${ }^{3}$ Department of Surgical Oncology, King Fahad Medical City, Riyadh, Saudi Arabia
}

Pseudomyxoma peritonei follows the perforation of a mucinous appendiceal or ovarian neoplasm which leads to intraperitoneal dissemination of mucinous implants that range in viscosity from purely liquid to a semisolid-like texture and that form on the peritoneal surfaces of the abdominal wall and visceral organs. ${ }^{1}$ Though the epithelial cells within the mucin proliferate and result in production of mucin, it rarely invades and hence does not metastasize into the blood stream or lymphatics. This mucinous material remains intra-abdominally and accumulates, eventually causing severe abdominal distension and anorexia from compression of the small bowel, which are the main causes of morbidity and mortality in untreated patients. The intraoperative findings of extensive carcinomatosis with mucinous implants accumulating in the pelvis and subphrenic regions are often daunting to general surgeons. ${ }^{2}$ Traditional treatments include repeated abdominal lavage of mucin, limited debulking of tumor, and systemic chemotherapy. ${ }^{3}$ However, these treatments are unable to adequately combat the reaccumulation of mucin that characterizes the failure of these treatments.

Cytoreductive surgery and perioperative intraperitoneal chemotherapy comprising hyperthermic intraperitoneal chemotherapy (HIPEC) with or without postoperative intraperitoneal chemotherapy (EPIC) has been unanimously regarded as the standard of care in specialized centers. ${ }^{4,5}$ A systematic review reporting the results of this

(C) Society of Surgical Oncology 2009

Published Online: 29 July 2009

T. C. Chua, BScMed (Hons)

e-mail: terence.chua@unsw.edu.au

D. L. Morris, $\mathrm{MD}, \mathrm{PhD}$

e-mail: david.morris@unsw.edu.au treatment in 10 specialized institutions of 863 patients showed a 5-year survival ranging between 52 and $96 \%$ from the time of cytoreductive surgery. ${ }^{6}$ Overall survival rates of 10 years have also been reported to be about $85 \%{ }^{7,8}$ In our institution, our perioperative intraperitoneal regimen comprising HIPEC and EPIC has resulted in a 5year survival of $75 \%$ and a median progression-free survival of 40 months. ${ }^{9}$ Further, a subgroup of the 106 patients treated has shown that perioperative intraperitoneal chemotherapy at the time of surgery for recurrent disease (second operation) significantly reduces subsequent risk of recurrence (third operation or death from 48 to 5\%) (unpublished data). Cytoreductive surgery involves an extensive surgical debulking through a peritonectomy procedure and is followed by administering perioperative intraperitoneal chemotherapy. This treatment has been shown to reduce disease recurrence and prolong survival compared with a policy of debulking surgery alone. ${ }^{10,11}$ Hence emphasizing the efficacious role of perioperative intraperitoneal chemotherapy.

Perioperative intraperitoneal chemotherapy, as first described by Sugarbaker, comprised both intraoperative instillation of a hyperthermic intraperitoneal chemotherapy (HIPEC) and a postoperative instillation of normothermic early postoperative intraperitoneal chemotherapy (EPIC). Intraoperative instillation of chemohyperthermia has been shown to have dual purpose to attain microscopic cytoreduction through the heat and the cytotoxic agent. By combining these two modalities, a synergistic effect has been shown where the cytotoxic effect is enhanced because of the heat. ${ }^{12}$ EPIC is an older technique of administering intraperitoneal chemotherapy and is normally done during the first 5 postoperative days where it is intended to target any residual microscopic tumor cells on raw peritoneal surfaces and surgical sites before the formation of adhesions. ${ }^{13}$ 


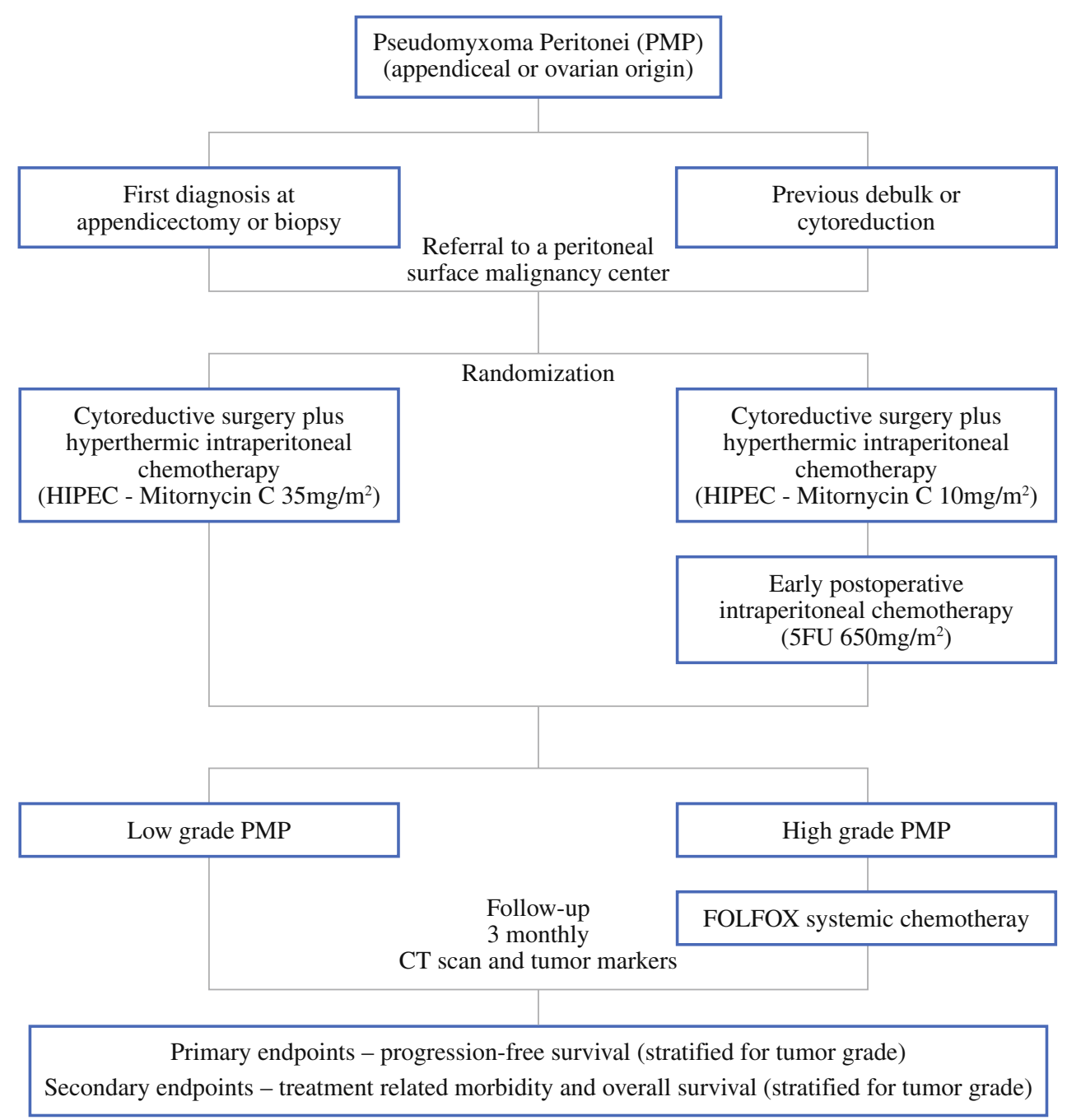

FIG. 1 Clinical pathway for randomization of patients with pseudomyxoma peritonei

Through the experience of surgeons, the use of EPIC has been curtailed because of its related complications, with the preference being to administer solely HIPEC after surgical cytoreduction and proceeding to adjuvant systemic treatments as required. A comparison of these two techniques of administering intraperitoneal chemotherapy in a selected cohort of 46 patients showed that EPIC was associated with higher rates of digestive fistulas (HIPEC $0 \%$ and EPIC $26 \% ; P=.02$ ), a poorer overall survival (HIPEC $54 \%$ at 5 years and EPIC $28 \%$ at 5 years; $P=.22$ ), and higher rates of intraperitoneal recurrences (HIPEC 26\% and EPIC 57\%; $P=.03$ ), therefore indicating that HIPEC is better tolerated and more efficient than EPIC at targeting microscopic residual tumor cells. ${ }^{14}$ The relative efficacy of administering HIPEC and EPIC compared with HIPEC alone as part of the package of perioperative intraperitoneal chemotherapy is unknown. Given that the rationale of perioperative intraperitoneal chemotherapy is to target microscopic disease, it would seem unjustified if the contributing survival advantage of administering EPIC after HIPEC is ignored purely for its morbidity and the convenience of postoperative care.

We therefore propose a clinical trial to examine the relative efficacy of the individual components of perioperative intraperitoneal chemotherapy through randomizing patients with pseudomyxoma peritonei into an arm that receives both HIPEC (Mitomycin C $10-12.5 \mathrm{mg} / \mathrm{m}^{2}$ ) and EPIC (5FU $\left.650 \mathrm{mg} / \mathrm{m}^{2}\right)$ after surgical cytoreduction versus another arm that receives a high dose of HIPEC (Mitomycin C $35 \mathrm{mg} / \mathrm{m}^{2}$ ) only (Fig. 1). Patients will be treated similarly on protocol with survival analysis stratified according to disease histology based on low-grade [diffuse peritoneal adenomucinosis (DPAM) and peritoneal mucinous carcinomatosis intermediate (PMCA-I)] and high-grade (PMCA) tumors. ${ }^{15}$ Through this trial, the relative efficacy of EPIC as part of the perioperative intraperitoneal chemotherapy regimen or a high dose of HIPEC alone, which was previously reported to be associated with significant risk of bone marrow toxicity, 
would be established as evidenced-based practice. ${ }^{16}$ Further, the morbidity associated with EPIC will also be elucidated from the results of this trial. We call upon institutions worldwide to participate in this effort to establish evidencebased standard of care for pseudomyxoma peritonei.

\section{REFERENCES}

1. Ronnett BM, Zahn CM, Kurman RJ, Kass ME, Sugarbaker PH, Shmookler BM. Disseminated peritoneal adenomucinosis and peritonealmucinous carcinomatosis. A clinicopathologic analysis of 109 cases with emphasis on distinguishing pathologic features, site of origin, prognosis, and relationship to "pseudomyxoma peritonei”. Am J Surg Pathol. 1995;19:1390-408.

2. Sugarbaker PH, Ronnett BM, Archer A, Averbach AM, Bland R, Chang D, et al. Pseudomyxoma peritonei syndrome. Adv Surg. 1996;30:233-80.

3. Mann WJ, Wagner J, Chumas J, Chalas E. The management of pseudomyxoma peritonei. Cancer. 1990; 66:1636-40.

4. Moran B, Baratti D, Yan TD, Kusamura S, Deraco M. Consensus statement on the loco-regional treatment of appendiceal mucinous neoplasms with peritoneal dissemination (pseudomyxoma peritonei). J Surg Oncol. 2008;98:277-82.

5. Sugarbaker PH. New standard of care for appendiceal epithelial neoplasms and pseudomyxoma peritonei syndrome? Lancet Oncol. 2006;7:69-76.

6. Yan TD, Black D, Savady R, Sugarbaker PH. A systematic review on the efficacy of cytoreductive surgery and perioperative intraperitoneal chemotherapy for pseudomyxoma peritonei. Ann Surg Oncol. 2007;14:484-92.

7. Baratti D, Kusamura S, Nonaka D, Cabras AD, Laterza B, Deraco M. Pseudomyxoma peritonei-Biological features are the dominant prognostic determinants after complete cytoreduction and hyperthermic intraperitoneal chemotherapy. Ann Surg. 2009;249: 243-9.

8. Yan TD, Bijelic L, Sugarbaker PH. Critical analysis of treatment failure after complete cytoreductive surgery and perioperative intraperitoneal chemotherapy for peritoneal dissemination from appendiceal mucinous neoplasms. Ann Surg Oncol. 2007;14: 2289-99.

9. Chua TC, Yan TD, Smigielski ME, Zhu KJ, Ng KM, Zhao J, et al. Long-term survival in patients with pseudomyxoma peritonei treated with cytoreductive surgery and perioperative intraperitoneal chemotherapy: 10 years of experience from a single institution. Ann Surg Oncol. 2009;16:1903-11.

10. Gough DB, Donohue JH, Schutt AJ, Gonchoroff N, Goellner JR, Wilson TO, et al. Pseudomyxoma peritonei. Long-term patient survival with an aggressive regional approach [see comment]. Ann Surg. 1994;219:112-9.

11. Miner TJ, Shia J, Jaques DP, Klimstra DS, Brennan MF, Coit DG. Long-term survival following treatment of pseudomyxoma peritonei: an analysis of surgical therapy [see comment]. Ann Surg. 2005;241:300-8.

12. Witkamp AJ, de Bree E, Van Goethem R, Zoetmulder FA. Rationale and techniques of intra-operative hyperthermic intraperitoneal chemotherapy. Cancer Treat Rev. 2001;27:365-74.

13. Sugarbaker PH, Graves T, DeBruijn EA, Cunliffe WJ, Mullins RE, Hull WE, et al. Early postoperative intraperitoneal chemotherapy as an adjuvant therapy to surgery for peritoneal carcinomatosis from gastrointestinal cancer: pharmacological studies. Cancer Res. 1990;50:5790-4.

14. Elias D, Benizri E, DiPietrantonio D, Menegon P, Malka D, Raynard B. Comparison of two kinds of intraperitoneal chemotherapy following complete cytoreductive surgery of colorectal peritoneal carcinomatosis. Ann Surg Oncol. 2006;14:509-14.

15. Bradley RF, Steward JH, Russell GB, Levine EA, Giesinger KR. Pseudomyxoma peritonei of appendiceal origin: A clinicopathologic analysis of 101 patients uniformly treated at a single institution, with literature review. Am J Surg Pathol. 2006;30: $551-9$.

16. Smeenk RM, Verwaal VJ, Zoetmulder FAN. Toxicity and mortality of cytoreduction and intraoperative hyperthermic intraperitoneal chemotherapy in pseudomyxoma peritonei-a report of 103 procedures. Eur J Surg Oncol. 2006;32:186-90. 